\title{
DEGRADATION OF JUNCTION PARAMETERS OF AN ELECTRICALLY STRESSED NPN BIPOLAR TRANSISTOR
}

\author{
N. TOUFIK, F. PÉLANCHON and P. MIALHE* \\ C.E.F., University of Perpignan, 52 av. de Villeneuve, F-66860 Perpignan
}

(Received 20 April 2001; In revised form 15 May 2001)

\begin{abstract}
The effect of an electrical ageing on npn bipolar transistor has been studied. The current gain decreases substantially and the electrical properties are discussed. The emitter-base junction parameters are degraded during the electrical stress experiments. Both the amplitude and the rate of this degradation depend on the stress duration. The evaluation of these parameters allows to discuss hot carrier degradation process, to estimate the stress magnitude and to control the device.
\end{abstract}

\section{INTRODUCTION}

The bipolar transistor, one of the most important semiconductor devices, has had an unprecedented impact on the electronic industry in general and on solid state research in particular [1].

Degradation of the performance of silicon bipolar transistors by an electrical stress $[2,3,4,5]$ is an important part of reliability considerations. A shift of the threshold voltage is observed, the carrier mobility, the current gain of the bipolar transistor, the leakage current of the reverse-biased $p-n$ junction, the emitter series resistance and the ideality factor of the $\mathrm{p}-\mathrm{n}$ junction are degraded [5].

The current gain $I_{C} / I_{B}$ of bipolar transistors strongly decreases when the oxide over the emitter-base junction is damaged [3,4]. This can occur in normal operation conditions since, when the emitter-base junction is reverse-biased [3,4], hot carried are created and the base current $I_{B}$ increases. It has been generally assumed $[3,6]$ that the excess

${ }^{*}$ Corresponding author. E-mail: mialhe $@$, univ-perp.fr 
base current $\Delta I_{B}$ is caused primarily by interface states created in the oxide over the emitter-base junction during the stress.

This work shows out the effects of an electric ageing experiments. The current gain of the transistor, and both the recombination current and the ideality factor of the emitter-base junction have been studied according to the stress duration. The results obtained with different stress conditions lead to point out two degradations processes: the main process consists in the increase of the recombination in the vicinity of the space-charge region in the emitter-base junction.

\section{METHOD}

\section{2a. Electrical Stress}

An electrical ageing [3] of npn bipolar transistors has been performed in order to investigate the gradual degradation in time of the emitterbase junction parameters. It is attributed to hot carrier injection in the space charge region of the emitter-base interface $[3,4]$ and involves different complex mechanisms.

The devices used in this experiment were $n^{+}-p-n$ silicon bipolar transistor, manufactured $2 \mathrm{~N} 2222 \mathrm{~A}$ type. The electrical stressing was realized with a reverse bias, $V_{B E}=-8 \mathrm{~V}$, applied to the emitter-base junction and the collector open (Fig. 1). The value, $60 \mathrm{~mA}$, of the reversed current biased the junction well into avalanche breakdown. The emitter-base junction parameters have been extracted from the junction current voltage characteristics of the transistor, before stress and for numerous stressing times.

\section{2b. Measurements}

$\beta$ is obtained through the measurements of the collector current $I_{C}$ and of the base current $I_{B}$ while the emitter-base junction is forward biased and the base-collector junction is reverse biased.

Junction parameters are obtained from a numerical analysis performed on experimental $I-V$ characteristic of the forward biased emitter-base junction [7]. 


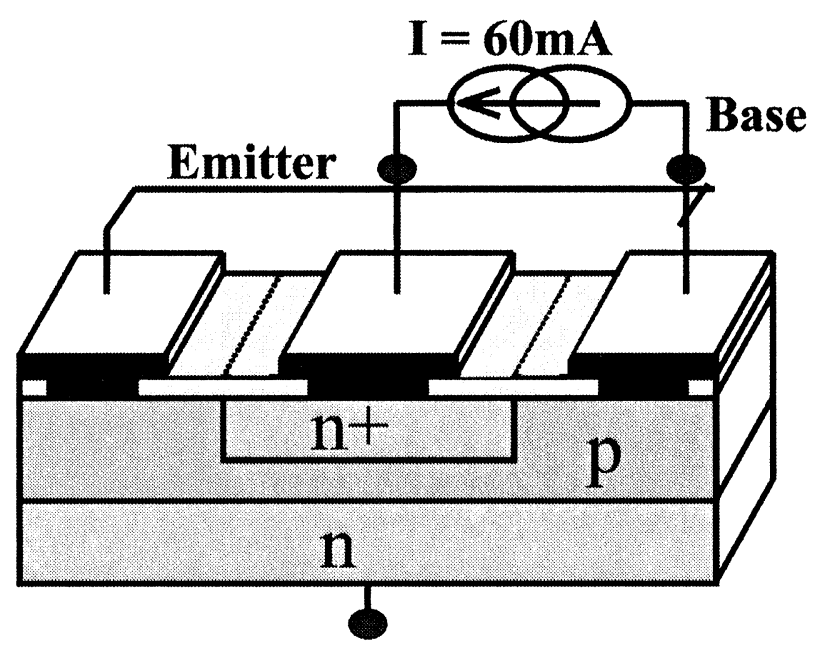

Collector

FIGURE 1 Experimental setup: electrical stress of a $n^{+}-p-n$ transistor.

The emitter-base junction is commonly represented [1] by either a single diode model (SEM) or a double diode model (DEM). Its characteristic can be described by the implicit $I-V$ equation:

$$
\begin{aligned}
I x & =\frac{V-R_{S} I}{R_{S l_{l}}}-I_{01}\left[\exp \left(\frac{V-R_{S} I}{V_{T}}\right)-1\right] \\
& -I_{02}\left[\exp \left(\frac{V-R_{S} I}{A V_{T}}\right)-1\right]
\end{aligned}
$$

where $T$ is the temperature, $V_{T}$ is the thermal potential, $A$ is the junction ideality factor, $R_{S}$ is the series resistance and $R_{S h}$ is the shunt resistance. $I_{01}$ is the diffusion-recombination current in the bulk of the junction and $I_{02}$ corresponds to the recombination current in the space charge region of the junction.

The parameters $A, I_{01}, I_{02}, R_{S}, R_{S h}$ are extracted by the software PARADI [8] available in our laboratory. 


\section{RESULTS AND DISCUSSION}

Figure 2 displays the variations of the current gain $\beta$ versus the emitter-base voltage for different aging times. The current gain degrades substantially, and the degradation is most severe at lower values of $V$. A strong degradation of $\beta$ appears after a short ageing time. This $\beta$ variation is clearly described by Figure 3 , where $\beta_{0}$ represents the $\beta$ value before any stress, $\Delta \beta=\beta-\beta_{0}$ and $\Delta \beta / \beta_{0}$ measures a kind of degradation rate.

This figure points out the strong decrease of $\beta$ during the first minutes of the electrical stress. Beyond a stress time around 5-10 min, the degradation rate is nearly constant.

This $\beta$ decrease is due to the base current $I_{B}$ increase as shown in Figure 4, it points out an increase of the recombination mechanisms in the base. In addition, it can be observed in Figure 4 that the slope of the $I_{B}$ curve increases with the stress duration. It is related to the increase of junction ideality factor which will be discuss below.

It can be concluded that the electric ageing creates defects localized near the emitter-base junction which degrades its performance [5].

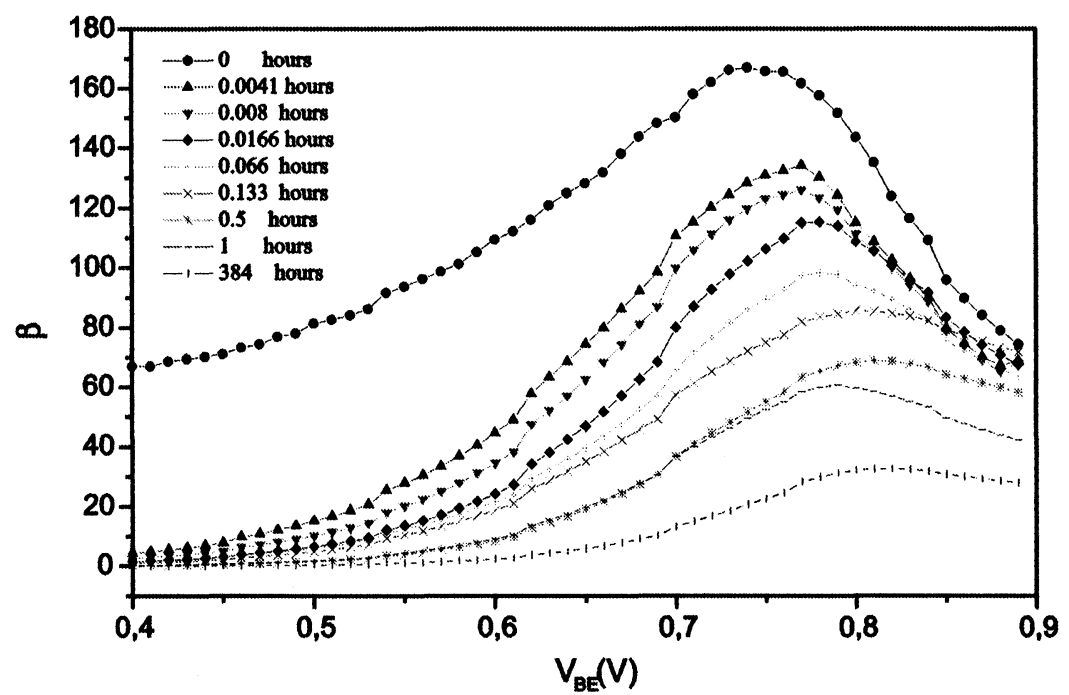

FIGURE 2 Current gain variations versus $V_{B E}$ for different stress times. 


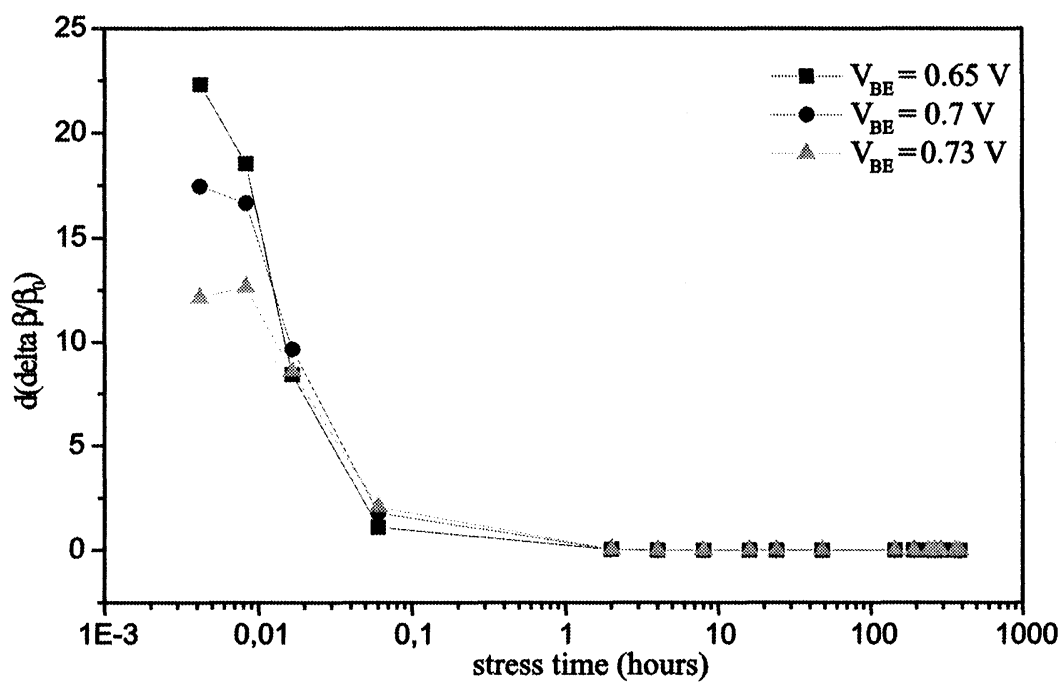

FIGURE $3 \Delta \beta / \beta_{0}$ versus the ageing time.

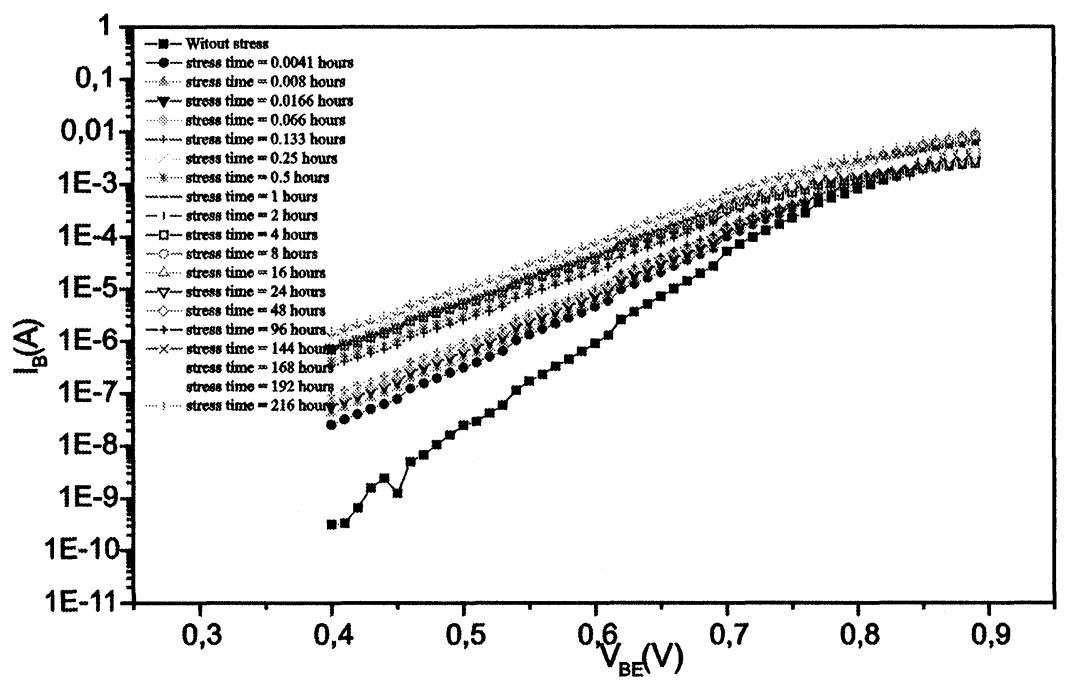

FIGURE 4 Variations of the base current versus $V_{B E}$. 


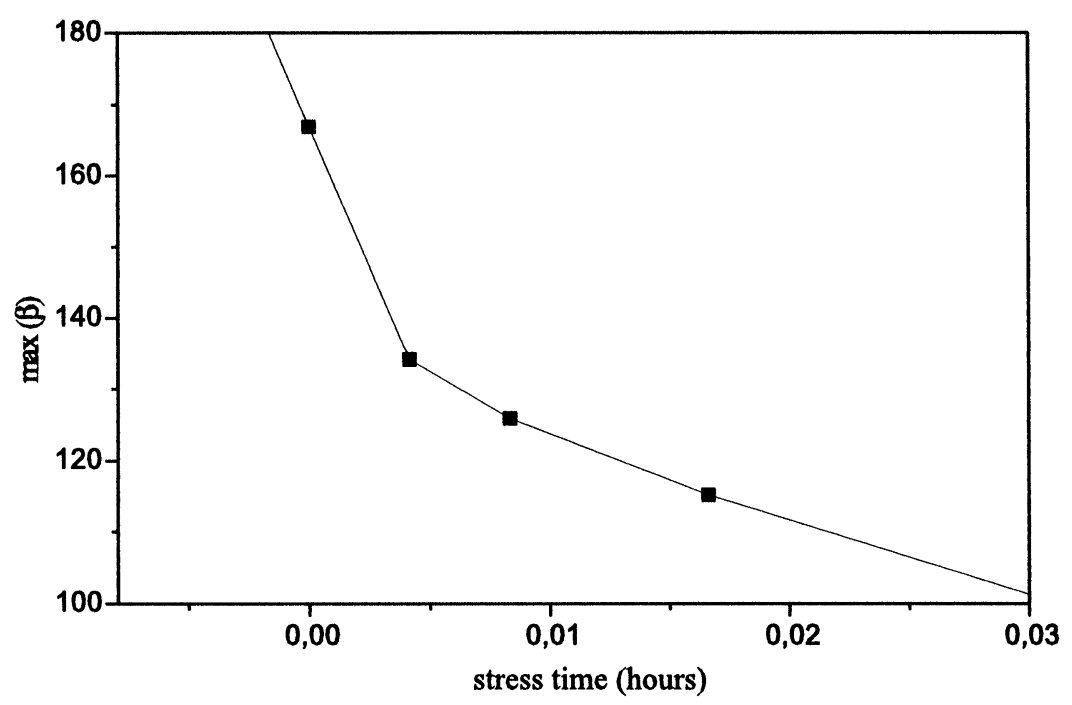

FIGURE 5 Variation of the maximum value of $\beta$ versus the stress time.

Figures 5, 6 and 7, showing respectively the variations, during the first stage of the ageing process, of the current gain, the diffusionrecombination current $I_{02}$ and the ideality factor of the emitter-base junction versus the stress time, allow a more detailed study. When the stress duration is lower than fifty seconds, the $\beta$ degradation (Fig. 5) is clearly related to the recombination process occurring in the very vicinity of the space-charge region of the junction since the ideality factor (Fig. 6) and the recombination current (Fig. 7) are increasing, which confirms previous results [3]. On the other hand, beyond the first fifty seconds, recombination current and the ideality factor stay quasi constants while $\beta$ still degrades: then, this degradation is unlikely to be due to the emitter-base junction recombination process. Other mechanisms, degrading the transistor behavior, appear, which have been considered in [9]. In order to understand these mechanisms, an other experimental study has been performed: the basecollector junction $I-V$ characteristics of the transistor have been measured, the emitter open, before and after the electrical stress. The evolution of these characteristics (Fig. 8) points out that the 


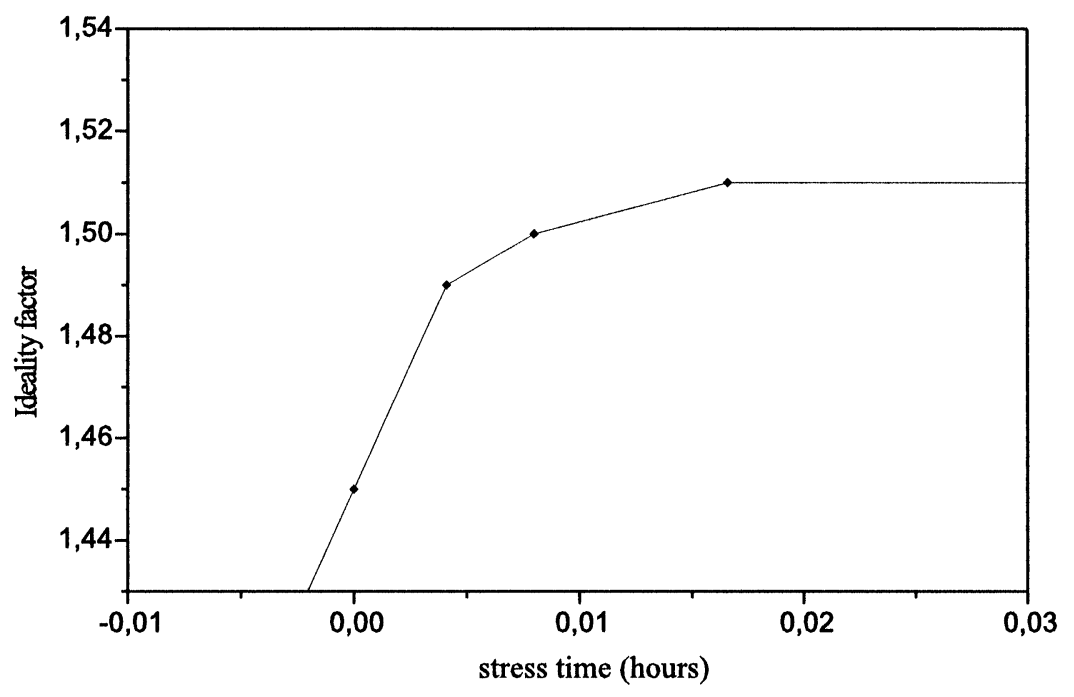

FIGURE 6 Evolution of the ideality factor versus the stress time.

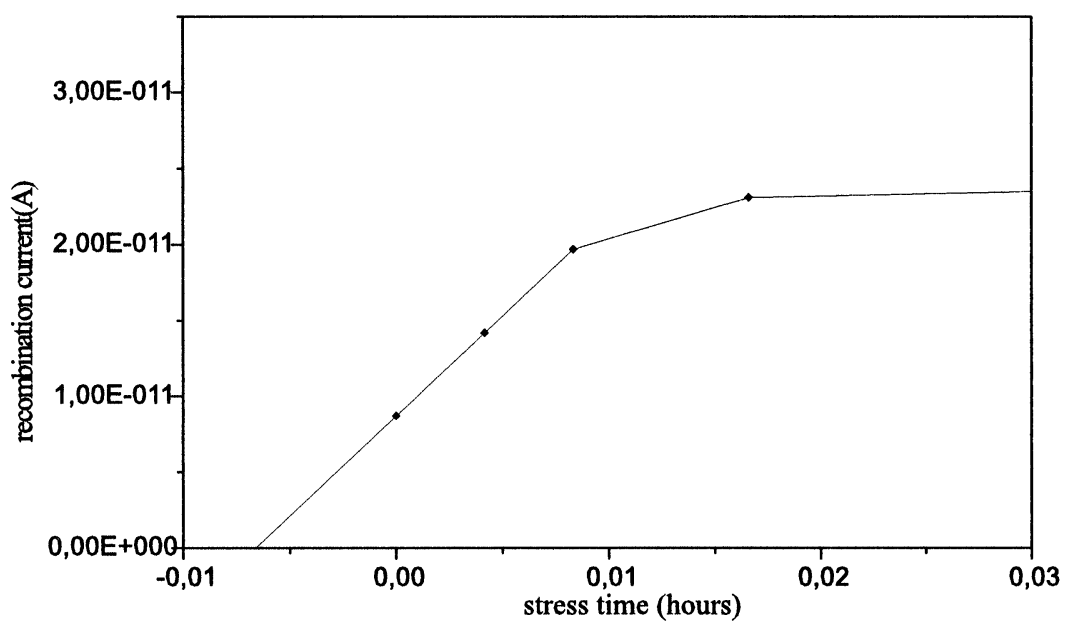

FIGURE 7 The extracted value of the reverse diffusion-recombination current time of the emitter-base junction versus the stress time. 


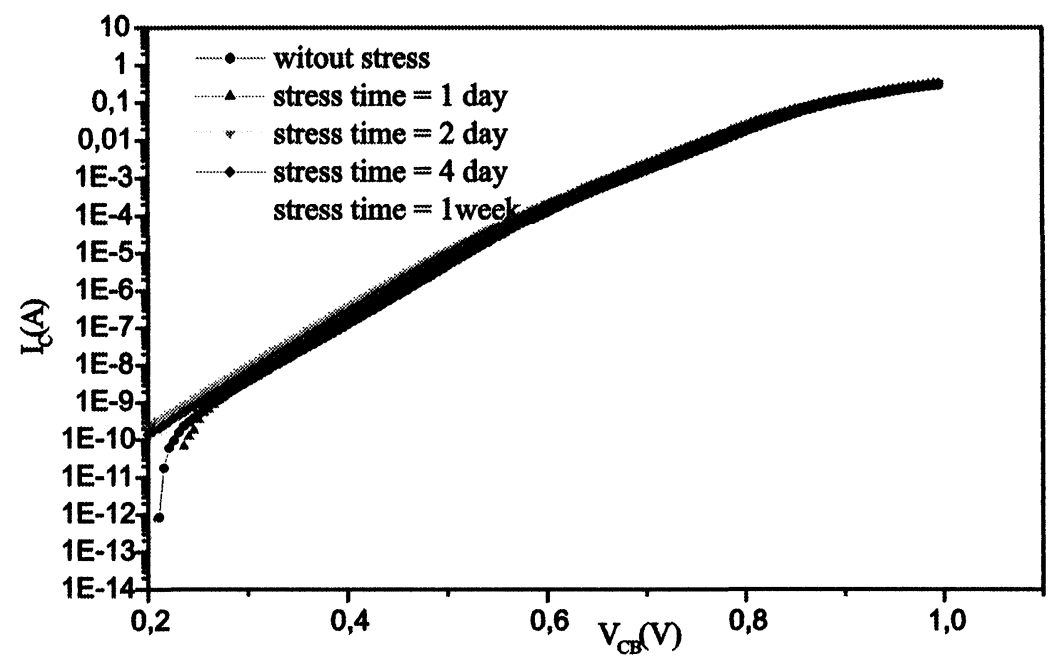

FIGURE 8 The base-collector junction $I-V$ characteristics before and after stress, the emitter open.

base-collector junction is not degraded by the stress. Then, the mechanisms responsible of the extra degradation of the transistor, are localized near the oxide-bulk interface.

Electrical stress degradation in bipolar junction transistors has been attributed [9] to hot carrier injection at the periphery of the emitter-base junction. Due to the high electric field in this region, hot electrons and holes can gain sufficient energy to generate active point defect. Increased charged defect populations cause the recombination current to increasing the base current and decreasing the current gain. A second class of mechanisms involving hot carriers liberating hydrogen have to be considered. Energetic holes and electrons can break $\mathrm{SiO}-\mathrm{H}$ bonds in the passivating $\mathrm{SiO}_{2}$ layer resulting in interfacial hydrogen center which are sensitive to degrade the current gain.

The parameters of the emitter-base junction appear strongly sensitive to the stress duration. It points out the degradation of the junction and the existence of a particular process involves in the transistor degradation. These results describe a direct observation of this process effect. 


\section{CONCLUSION}

A commercial npn transistor has been electrically stressed. Degradation of the emitter-base junction versus stress time has been observed and correlated, in the first stage of the stress process with an increase of both the diffusion-recombination current and the ideality factor.

The current gain of the transistor and of both the recombination current and the ideality factor of the emitter-base junction have been studied according to the ageing duration. The results obtained with different stress conditions lead to point out two degradations processes: the main one consists in the increase of the recombination in the vicinity of the space-charge region in the emitter-base junction.

\section{References}

[1] S. M. Sze (1981) Physics of Semiconductor Devices 2nd ed., (Wiley, New York).

[2] B. Boittiaux (1995) Les Composants Semiconducteurs. Lavoisier - Tec Doc, ISBN 2 7430-0068-4.

[3] S. L. Kosier, A. Wei, R. D. Schrimpf, D. M. Fleetwood, M. D. Delaus, R. L. Pease and W. E. Combs (1995) Physically based comparison of hot-carrier-induced and ionizing-radation-induced degradation in BJT's. IEEE Trans. Electron Devices 42, 436-444.

[4] M. S. Carrol, A. Neugroschel and C. T. Sah (1997) Degradation of silicon bipolar junction transistors at high forward current densities. IEEE Trans. Electron Devices 44, 110-117.

[5] N. Toufik, F. Pélanchon and P. Mialhe (2000) Effect of an Electrical Stress on NPN Transistor Parameters. The Journal of Non-Crystalline Solids (soumis).

[6] S. L. Kosier, R. D. Schrimpf, R. N. Nowlin and M. Fleetwood (1993) Charge separation for bipolar transistors. IEEE Trans. Electron Devices 40, 1276-1285.

[7] M. de la Bardonnie, N. Toufik, C. Salamé, S. Dib, P. Mialhe, A. Hoffmann and J.-P. Charles (1999) Junction parameters for silicon devices characterization. Microelectronics Reliability 39, 751-753.

[8] J.-P. Charles, I. Mekkaoui-Alaoui, G. Bordure and P. Mialhe (1985) A critical study of the effectiveness of the single and double exponential models. Solid-State Electronics 28, 807-820.

[9] M. de la Bardonnie, Dong Jiang, S. E. Kerns, D. V. Kens, P. Mialhe, J.-P. Charles and A. Hoffmann (1999) On the aging of avalanche light emission from silicon junctions. IEEE Trans. Electron Devices 46, 1234-1239. 

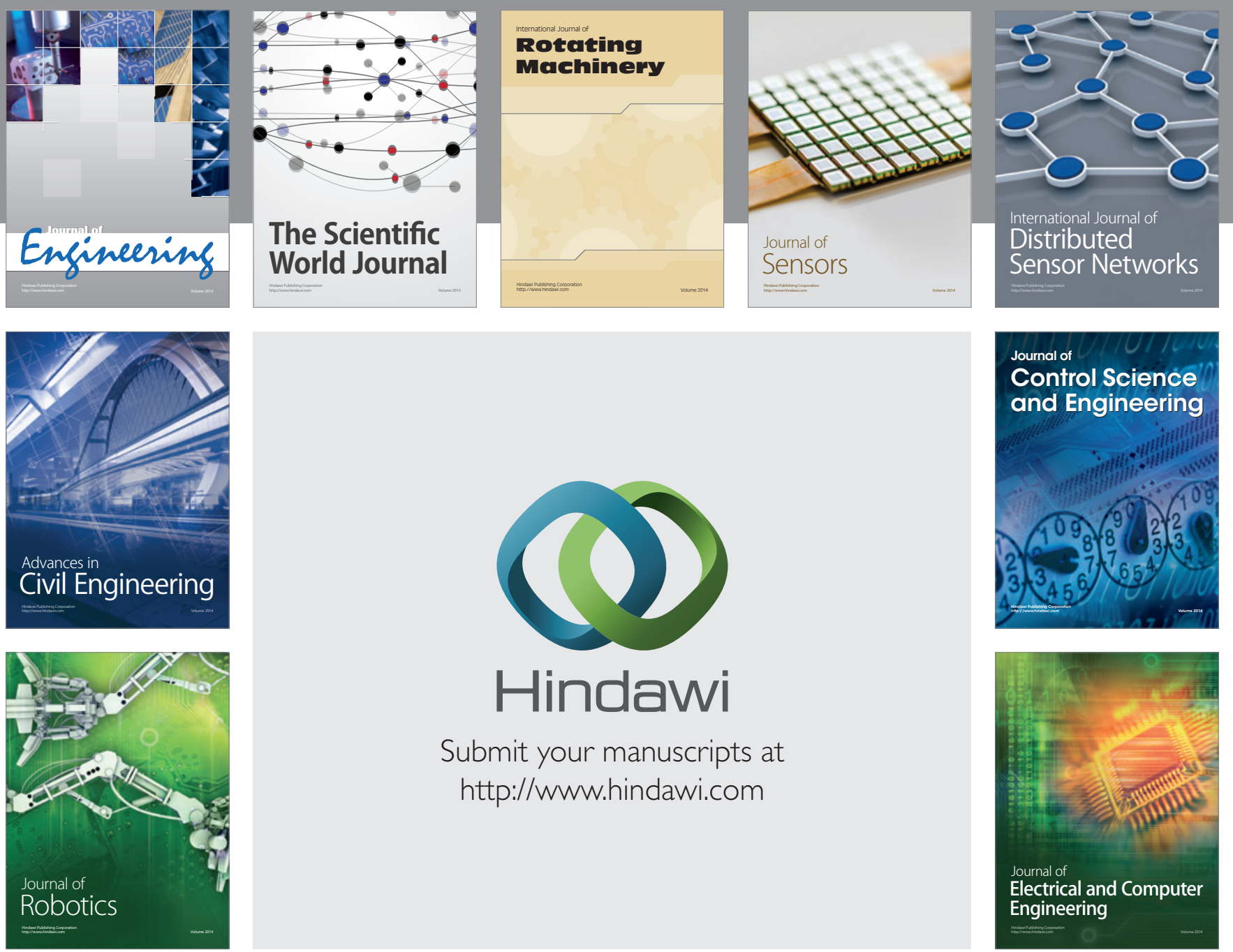

Submit your manuscripts at

http://www.hindawi.com
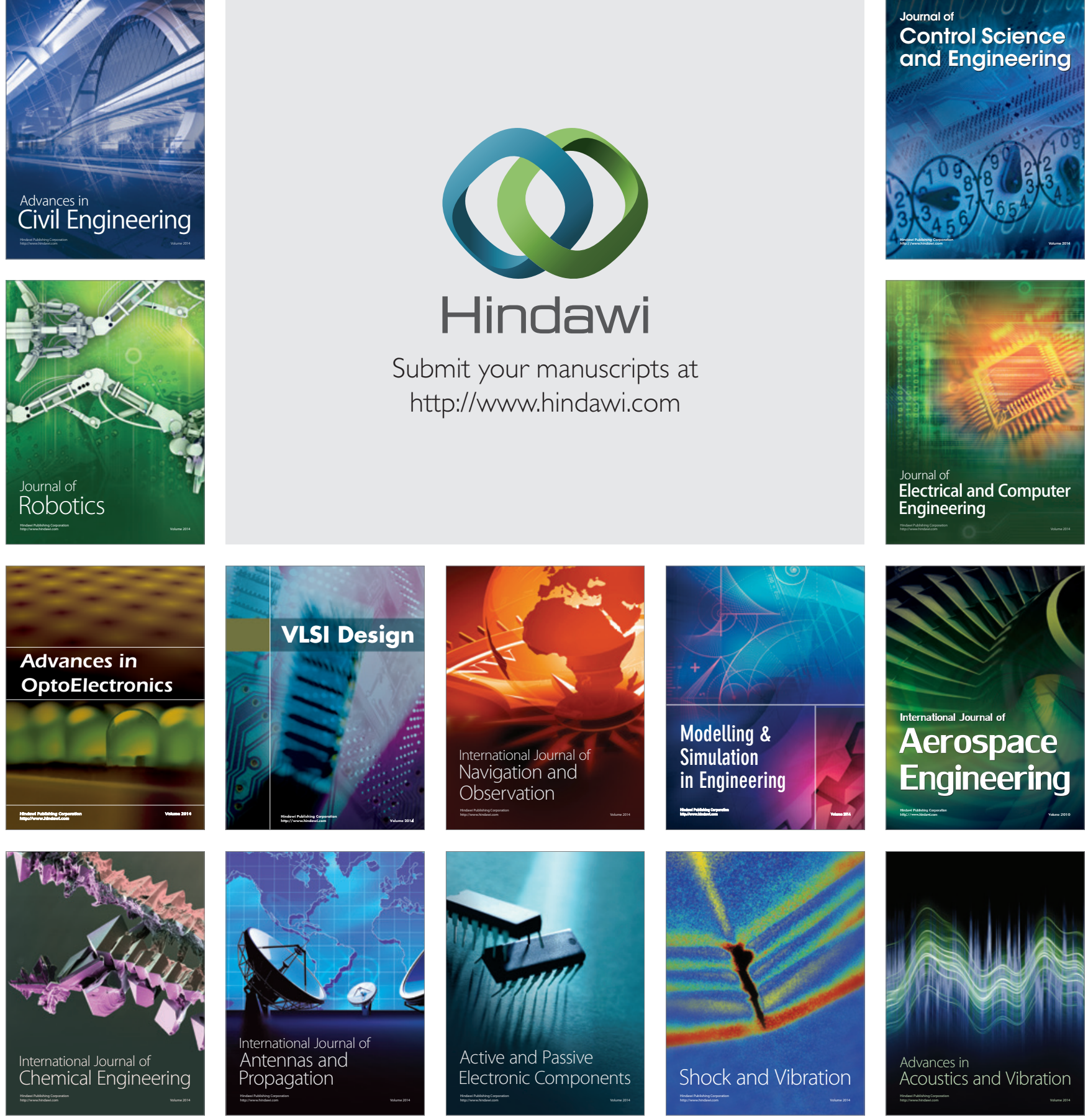